\title{
Cognitive Change, Dementia and Depression in Parkinson's Disease
}

\author{
Yaakov Stern
}

Cognitive change is a common manifestation of Parkinson's disease (PD). Specialized tests may be required to detect specific cognitive changes in otherwise functional patients. On the other end of the spectrum, recent studies have noted higher prevalence of dementia in PD than had been previously suspected. Depression is commonly observed in patients with PD, although there is some controversy about whether this is a manifestation of the disease itself, or simply a reaction to the disabling features of the disease.

Depression and dementia can co-exist in PD or depression can precede dementia. In this context, the case history of one patient we have followed is of interest. This 50 year old man had a 10 year history of PD. Sinemet treatment was initiated at age 44 and he responded well. Three years later, he developed depression which was successfully treated with 5-HTP. Three years after this he became significantly functionally and intellectually impaired, and had episodes of confusion, disorientation, agitation and aggression. A biopsy of the right frontal cortex revealed senile plaques, both with and without amyloid cores and a few neurofibrillary tangles and preliminary analyses suggest that ChAT activity is reduced. This case demonstrates the manifestation of both depression and dementia in a single individual. Wheth-

Yaakov Stern, PhD, is affiliated with the Departments of Neurology and Psychiatry and the Sergievsky Center, Columbia University, College of Physicians and Surgeons, New York, NY.

This work was supported by Federal Grants A G07370, A G07232, A G08702, and the Parkinson's Disease Foundation.

[Haworth co-indexing entry note]: "Cognitive Change, Dementia and Depression in Parkinson's Disease." Stern, Yaakov. Co-published simultaneously in Loss, G rief \& Care (The Haworth Press, Inc.) Vol. 8, No. 3/4, 2000, pp. 143-149; and: Parkinson's Disease and Quality of Life (ed: Côté et al.) The Haworth Press, Inc., 2000, pp. 143-149. Single or multiple copies of this article are available for a fee from The Haworth Document Delivery Service [1-800-342-9678, 9:00 a.m. - 5:00 p.m. (EST). E-mail address: getinfo@ haworthpressinc.com].

E 2000 by The Haworth Press, Inc. All rights reserved. 
er the depression was an early sign of the biological changes associated with $A D$ or represented an independent manifestation of PD is unclear.

\section{DEPRESSION IN PD}

Three forms of depression are most often reported: major depression, dysthymic disorder, and atypical depression with anxiety. ${ }^{1-3} M$ ajor depression is a chronic dysphoric mood associated with changes in appetite, sleep, concentration, and accompanied by psychomotor retardation. Dysthymic disorder is a similar but intermittent mood disturbance with periods of relatively normal mood. ${ }^{4}$ A typical depression, accompanied by intermittent anxiety has recently been described. ${ }^{3}$ The use of well defined diagnostic criteria for depression, such as those in DSM -III-R, ${ }^{4}$ is crucial to ensure that diagnosis is as reliable as possible.

Depression of moderate to mild intensity is most frequently reported, and has been most frequently investigated. A s many as $40 \%$ of patients with PD will become depressed during their illness with $25 \%$ of these patients experiencing depression prior to the onset of overt motor manifestation of PD or within a year of their onset. Dooneief et al. ${ }^{5}$ estimated the prevalence of depression in PD to be about 47\%, while the incidence was about $1.9 \%$ annually. The cumulative risk was about $1.8 \%$ per year. In some cases, depression can be associated with mild intellectual dysfunction ${ }^{6}$ and even frank dementia. ${ }^{7}$

Some investigators argue that because PD and primary depression share some clinical manifestations, the resultant higher frequency of mood alterations might be expected. A relationship between the severity of depression and the severity of physical manifestations has been inconsistently observed, which would favor this concept. ${ }^{8} \mathrm{~A}$ lso, patients with equally physically disabling disorders are often found to be depressed. For example, one study found patients with rheumatoid arthritis to be as depressed as those with PD because of the similar degree of impairment in functional activities of daily life. ${ }^{8}$

On the other hand, Santamaria et al. ${ }^{9}$ reported the onset of depression prior to, or just after, the onset of PD. This would occur at a time when, presumably, the motor manifestations of PD are minimal, suggesting that biological changes may occur which predispose to a mood disorder. A Iso, many investigators have not found an association between the severity of motor manifestations of PD and depression. Finally, depression has been associated with serotonergic changes in PD, ${ }^{1-2}$ suggesting that disease-related biochemical changes may predispose to depression. 


\section{DEMENTIA IN PD}

DSM -III-R ${ }^{4}$ criteria for dementia require documented intellectual decline as well as decline in the ability to perform social or occupational function. This functional incapacity must be a result of dementing changes as opposed to physical disability. In PD, it is particularly important to attempt to ascertain the source of difficulty with these behaviors: is the patient incapable of accomplishing them, is there a physical disability that is impeding him, is he too apathetic to carry them out?

The extent to which the dementias of Parkinson's disease (PD) and Alzheimer's disease (AD) overlap remains controversial. As B rown and M arsden ${ }^{10}$ point out, some investigators have concluded that the two dementias differ in etiology and phenomenology ${ }^{11}$, while, after reviewing the same literature, others remain unconvinced. 10,12,13 Several extensive reviews of comparative studies exist. 13,10-14 While many aspects of memory loss are comparable in demented PD and AD patients, change scores demonstrate a feature of memory loss that is more severe in AD.15 Thus while dementia in the two diseases is similar in may ways, subtle differences can be detected. Dementia in PD is most likely heterogenous, with some cases due to concomitant AD, some to a "pure" PD dementia, while others due to Lewy body disease.

Although several earlier studies had suggested the prevalence could be as high as $90 \%, 16$ B rown and $\mathrm{M}$ arsden ${ }^{17}$ argued that those prior investigations had not used criterion-based diagnoses and that as a result most of the estimates were inflated. This was quickly supported by other investigators, who reported prevalence rates between 10 and 16\%.18-21 However, few studies calculated age-specific rates of dementia which might be a better method for investigating prevalence because there is a correlation between age and dementia. In our hospital-based study the prevalence estimate for dementia was $21 \%$ in patients whose motor manifestations began after age 70.21

A prevalence study of PD with and without dementia an area of Northern $M$ anhattan found that $41.3 \%$ of the 179 patients identified in the community were demented.22 The overall crude prevalence of PD with dementia was 41.1 per 100,000 persons (over age 35: 90.8 per 100,000). The age-specific prevalence of PD-dementia al so increased with age, parallel to the increase in PD overall, from 0.5 per 100,000 below age 50 to 787.1 per 100,000 above age 80 . The prevalence standardized to the estimated distribution of the 1988 US population, ranged from 5.3 per 100,000 between ages 35 and 64 to 62.5 per 100,000 over age 75 . The frequency of PD-dementia was estimated to be less than one-tenth of that for AD.

M ayeux et al. ${ }^{23}$ calculated the incidence rate of dementia after nearly 5 years of follow-up of a hospital-based cohort to be 69 per 1000 person-years of follow-up. As age increased, the cumulative incidence, or cumulative risk, 
of dementia in the cohort also increased. By age 85, the risk of dementia in this cohort had reached over $65 \%$. Rajput et al.24 found the 5 year cumulative probability of developing dementia in patients with PD to be twice that for age- and sex-matched controls.

These studies suggest that the frequency of dementia is much higher than that previously estimated by prevalence studies. Incidence rates provide a better estimate of the frequency of dementia because it is not affected by mortality. The New York study 23 indicated an incidence rate of 69 per 1000 person years or $6.9 \%$. Compared to standard populations such as the city of Rochester, Minnesota, or a cohort of men in the Baltimore Longitudinal Study, this rate is 6 to 12 times the rate of dementia that would be expected to develop among similarly aged healthy individuals. In terms of the individual patient, this study also indicated that the cumulative risk of dementia was as high as $65 \%$ by 85 years of age. M oreover, the likelihood of death is significantly greater for demented patients.

\section{COGNITIVE CHANGES IN NONDEMENTED PATIENTS}

Investigators have used PD as a model for studying the role of the basal ganglia in cognition. While the basal ganglia certainly function in many different capacities, Stern ${ }^{25}$ suggested a working hypothesis for summarizing behavioral functions of the basal ganglia and in turn the nature of cognitive changes in PD: The basal ganglia are part of a cortico-striatal system that aids in planning and modulating ongoing activity in the absence of external guidance. The cortico-striatal system referred to involves projections from the cortex to the basal ganglia, and some form of feedback returning to the cortex. Prefrontal cortex is probably most involved in this system. The word "activity" is specifically vague in order to encompass behavior ranging from motor control functions to purely intellectual tasks. The tasks share the need for planning and sequencing units of behavior, monitoring ongoing behavior and modifying to continue to meet task demands. This often entails initiating the shift from one unit of behavior to the next when appropriate. M odulating ongoing activity becomes especially important when the environment presents no cues to guide behavior or to indicate whether it is correct. Several categories of cognitive changes noted in early PD are encompassed in this hypothesis, including visuospatial, executive, motor programming and possibly memory changes.

Impairment in various aspects of visuospatial function have been noted in PD. 26-27 These may be a function of patients' inability to plan and conduct motor tasks that require such skills. Difficulties with motor programming have been noted using several paradigms. ${ }^{28-30} \mathrm{M}$ ost studies have not noted a 
primary deficit in spatial perception, although deficits have been noted on specific non-motor visuospatial tasks. ${ }^{31}$

Executive dysfunction was noted originally on the Wisconsin Card Sort. ${ }^{32}$ Similar results have been noted on tasks such as the $O \mathrm{dd} M$ an $\mathrm{O}$ ut, as well as other tasks requiring "set shifting." $33-35$ In contrast, there is less consistent evidence for deficit on tasks requiring maintenance of a specific response set. 35

Some degree of memory loss does appear to be present in nondemented patients with PD, 27 although studies suggest intact ability to register, store and consolidate information. Problems have been noted with delayed response and alternation, recency discrimination, temporal ordering, and dating capacity. It has been suggested that this may in part be related to executive processes such as difficulty organizing strategies for storage or retrieval. ${ }^{12}$

Stern and Langston ${ }^{36}$ studied M PTP-induced Parkinsonism, a pure dopamineeficiency syndrome, that occurs without an associated dementia. They found impairment in visuospatial, executive, and verbal fluency tasks all of which require the ability to sequence mental activity. Similar, but less severe, deficits are also found in asymptomatic (for Parkinsonian motor manifestations) patients with limited exposure to M PTP 37 which may imply that there are certain a dopamine-specific behaviors. In contrast, Dubois et al. ${ }^{38}$ found than small doses of scopolamine, an anticholinergic, which did not affect memory in healthy elderly produced adverse effects on memory in patients with PD who were not demented. This may suggest that some cognitive changes in nondemented patients are unrelated to dopaminergic depletion.

\section{CONCLUSIONS}

Cognitive change, dementia and depression are important features of PD. They complicate treatment of the disease and can be more disabling than the motor features. Careful attention to these aspects of the disease is warranted.

\section{REFERENCES}

1. Mayeux R, Stern Y, Cote L, Williams JBW. Altered serotonin metabolism in depressed patients with Parkinson's disease. Neurology 1984; 34:642-646.

2. Mayeux R, Stern Y, Williams J BW. Clinical and biochemical features of depression in Parkinson's disease. Am J Psychiatry 1986; 143:756-759.

3. Schiffer RB, K urian R, Rubin A, Boer S. Parkinson's disease and depression: evidence for an atypical affective disorder. Am J Psychiat 145:1020-2 (1988).

4. A merican Psychiatric A ssociation, Diagnostic and Statistical $M$ anual of $M$ ental Disorders, Third Edition-Revised, Washington, D.C. 1987. 
5. D oonei ef G, M irabello E, B ell K, M arder K, Stern Y, M ayeux R. A n estimate of the incidence of depression in idiopathic Parkinson's disease. A rch N eurol 1992; 49: 305-307.

6. Starkstein SE, B olduc PL, M ayberg HS, Preziosi TJ, Robinson RG. Cognitive impai rments and depression in Parkinson's disease: a follow-up study. J N eurol Neurosurg Psychiatry 1990; 53: 597-602.

7. Sano M, Stern Y, Williams J, Cote L, Rosenstein R, M ayeux R. Co-existing dementia and depression in Parkinson's disease. A rch Neurol 1989; 46:1284-1287.

8. Gotham A M , Brown RG, M arsden CD. Depression in Parkinson's disease: a quantitative and qualitative analysis. J Neurol Neurosurg Psychiatr 1986; 49:381-389.

9. Santamaria J, Tolosa E, Valles A. Parkinson's disease with depression: a possible subgroup of idiopathic parkinsonism. Neurology 1986;36:1130-1133.

10. B rown RG, M arsden CD. 'Subcortical dementia' : the neuropsychological evidence. Neuroscience 1988;25:363-387.

11. Cummings J L. Subcortical dementia. Neuropsychology, neuropsychiatry and pathophysiology. B r Psychiat 1986; 149:682-697.

12. Dubois B, Boller F, Pillon B, A gid Y. Cognitive deficits in Parkinson's disease. In Boller R, Grafman J (Eds.) Handbook of Neuropsychology, Vol 5, Elsevier, A msterdam, 1991:195-240.

13. Whitehouse PJ. The concept of subcortical dementia: another look. Ann Neurol 1986; 19:1-6.

14. Mahler ME, Cummings J L. Alzheimer's disease and the dementia of PD: comparative investigations. A lzheimer Dis Assoc Disord 1990;4:133-149.

15. Helkala EL, Laulumaa V, Soininen $H$, Riekkinen PJ. Recall and recognition memory in patients with Alzheimer's and Parkinson's diseases. Ann Neurol 1988;24:214-217.

16. Pirozzolo FJ, Hansch EC, M ortimer JA, Webster DO Kuskowski MA. Dementia in Parkinson's disease: A neuropsychological analysis. Brain $\&$ Cognition 1982; 1:71-81.

17. Brown RG, M arsden CD. How common is dementia in Parkinson's disease. Lancet 1984;1:1262-5.

18. Lees A J. Parkinson's disease and dementia. Lancet 1985;1:43-4.

19. Taylor A, Saint-Cyr JA, Lang AE. Dementia Prevalence in Parkinson's disease. Lancet 1985;1:1037.

20. Sutcliffe RL G. Parkinson's disease in the district of the N orthhampton Health A uthority, U nited K ingdom. A Study of prevalence and disability. A cta N eurol Scand 1985;72:363-379.

21. M ayeux R, Stern $Y$, R osenstein R, M arder K, Hauser WA, Cote L, Fahn S. An estimate of the prevalence of dementia in idiopathic Parkinson's disease. Arch Neurol. 1988; 45: 260-263.

22. M ayeux R, Denaro J, Hemenegildo N, M arder K, Tang M X, Cote LJ , Stern Y. A population-based investigation of Parkinson's disease with and without dementia: Relationship to age and gender. A rch N eurol 1992;49:492-497. 
23. M ayeux R, Chen J, M irabello E, M arder K, B ell K, Dooneief G, Stern Y. A n estimate of the incidence of dementia in patients with idiopathic Parkinson's disease. Neurology 1990; 40: 1513-1517.

24. Rajput $A H, O$ fford $K P, B$ eard CM , K urland LT. A case-control study of smoking habits, dementia, and other illnesses in idiopathic Parkinson's disease. Neurol. $1987 ; 37: 226-232$.

25. Stern Y. The Basal Ganglia and Intellectual Function. In: Schneider J. (Eds.) Basal Ganglia and Behavior: Sensory Aspects of M otor Functioning. Hans Huber, Toronto, 1987, pp 169-74.

26. Proctor F, Riklan M, Cooper ST, Teuber HL. Judgement of visual and postural vertical by Parking' onian patients. Neurology 1964; 14:287-293.

27. Levin BE, Llabre M M, Weiner WJ. Cognitive impairments associated with early Parkinson's disease. Neurology 1989;39: 557-561.

28. Flowers K. Lack of prediction in the motor behavior of parkinsonism. Brain 1978;101:35-52.

29. Stern Y, M ayeux R, Rosen J , L ison J . Perceptual motor dysfunction in Parkinson's disease: A deficit in sequential and predictive voluntary movement. J. Neurol Neurosurg Psychiatry 1983;46:145-151.

30. Bloxham, C.A., M indel, T.A., and Frith, C.D., Initiation and execution of predictable and unpredictable movements in Parkinson's disease. Brain, 107 (1984) 371-84.

31. Boller F, Passaflume D, K eefe NC, Rogers K, M orrow L, K im Y. Visuospatial impairment in Parkinson's disease: role of perceptual and motor factors. A rch N eurol 1984;41:485-490.

32. B owen FP. B ehavioral alterations in patients with basal ganglia lesions. In $M$. Yahr D (Ed). B asal Ganglia, Raven Press, New York, 1975:169-180.

33. L ees A J , Smith E. Cognitive deficits in the early stages of Parkinson's disease. Brain 1983; 106: 257-270.

34. Flowers KA, Robertson C. The effect of Parkinson's disease on the ability to maintain a mental set. J Neurol Neurosurg Psychiatry 1985;48:517-529.

35. Richards M, Cote LJ , Stern Y. Executive function in Parkinson's disease: setshifting or set maintenance? J Clin Exp Neuropsych 1993; 1 5:266-279.

36. Stern Y, L angston W. Intell ectual changes in pati ents with M PTP-induced parkinsonism. Neurology 1985; 35: 1506-1509.

37. Stern $Y$, Tetrud JW, M artin W RW et al. Cognitive change following M PTP exposure. Neurology 1990; 40: 261-264.

38. Dubois B, Danze F, Pillon B et al. Cholinergic-dependent cognitive deficits in Parkinson's disease. Ann Neurol 1987; 22: 26-30. 

Copyright of Loss, Grief \& Care is the property of Haworth Press, Inc. and its content may not be copied or emailed to multiple sites or posted to a listserv without the copyright holder's express written permission. However, users may print, download, or email articles for individual use. 